\title{
Contadores de histórias, ou quando a imaginação, a criação e a atenção nos ensinam como olhar com os ouvidos e ouvir com os olhos ${ }^{1}$
}

Maria Ignês Carlos Magno

Doutora em Ciências da Comunicaşão pela ECA/USP. Professora do Mestrado em Comunicação da Universidade Anhembi Morumbi e da Fundação Escola de Sociologia e Política de São Paulo.

E-mail: unsigster@gmail.com

Resumo: Toda obra cinematográfica, ainda que ficcional, trará em si traços da realidade de seu autor ou do público. Da mesma forma, mesmo as obras declaradamente documentais terão sua porcentagem de inspiração e releitura ficcional da realidade. O filme $O$ contador de histórias une esses dois elementos da criação artística e cinematográfica ao recontar uma história real, com elementos ficcionais retirados não só da releitura do enredo, como da própria natureza do personagem que o protagoniza. Com base nessa reflexão, a resenha faz a análise da citada obra em confronto com os momentos histórico e cultural atuais do país.

Palavras-chave: Cinema, Febem, criação cinematográfica, infância e juventude.
Abstract: All cinematographic work, albeit fictional, bring itself traces from its author's or the audience's reality. In the same way, even the documentaries will have their percentage of inspiration and fictional reinterpretation of reality. The motion picture O contador de histórias [The Storyteller] joins these two elements - artistic and cinematographic creation- when retelling a real story, with fictional elements taken not only from the plot reinterpretation, but also from the protagonist's nature. Based on this reflection, this article analyses the cited work confronting it with this country's current cultural and historical context.

Keywords: Cinema, Febem, cinematrographic creation, childhood and youth.

Acompanhar o processo de criação de um roteiro e ver o filme é poder flagrar os segredos da metamorfose por que passa a palavra até faiscar na tela.

Silvio Back $^{2}$
1. Título original - O contador de histórias Gênero: Drama Direção: Luiz Villaça Roteiro: Luiz Villaça, Maurício Arruda, José Roberto Torero e Mariana Veríssimo

Produção: Francisco Ramalho Jr. e Denise Fraga Música: André Abujamra Fotografia: Lauro Escorel Direção de arte: Valdy Lopes

Figurino: Cássio Brasil Edição: Umberto Martins e Maria Altberg Ano: 2009

Duração: 1h e 50 minutos Site oficial: <http:// wwws.br.warnerbros.com/ ocontadordehistorias/ site>

2. BACK Silvio A guerra dos pelados: roteiro do filme. São Paulo: Annablume, 2008. p. 9. 
comunicação \& educação • Ano XVII • número 1 • jan/jun 2012

\section{INTRODUÇÃO}

É preciso desejo e é preciso amor para se para fazer um filme ${ }^{3}$, porque filmar é arriscar, arriscar-se. Também é preciso desejo e amor para escrever e ensinar. A linha que separa a coragem do risco é tênue. Transformar um texto literário em um filme exige que outros elementos necessários a sua elaboração e produção sejam acionados - e um deles é a criação do roteiro. A feitura de um filme pede instâncias artísticas e técnicas que envolvem pesquisa, criação de um argumento e a sensibilidade dos criadores e realizadores. Mesmo quando a linguagem cinematográfica usada é a documental, para nos dar a sensação de realidade, um filme é sempre inspiração, ficção, trans-criação de outro texto. E o "outro texto" em questão é a trágica história de Roberto Carlos, ex-interno da Febem (antiga Fundação Estadual para o Bem-Estar do Menor) e hoje contador de histórias - um pedagogo contador de histórias. A escolha do filme $O$ contador de histórias não se deu ao acaso; foi pensada porque trata da vida de um ex-Febem que driblou a violência e a marginalidade usando a imaginação para criar e contar histórias - e também para mostrar como os roteiristas, ao transformarem as palavras literárias em imagens, conseguiram, além de colocar em discussão os conflitos nas relações familiares, as temáticas ocultas e aparentemente deslocadas ou pouco estudadas no ambiente escolar, nos dar oportunidade de pensar nas mudanças históricas ocorridas na cartografia da família, da escola e das Instituições Oficiais responsáveis pelos que tiveram e têm a infância sequestrada.

\section{QUANDO A IMAGINAÇÃO DRIBLA A VIOLÊNCIA}

O filme $O$ contador de histórias (2009), de Luiz Villaça, como muitos que vemos na TV ou cinema, é declaradamente baseado em fatos reais. Fatos que

3. SALLES, Francisco Luiz de Almeida. Cinema e verdade. São Paulo: Companhia das Letras, 1988. p. 46.

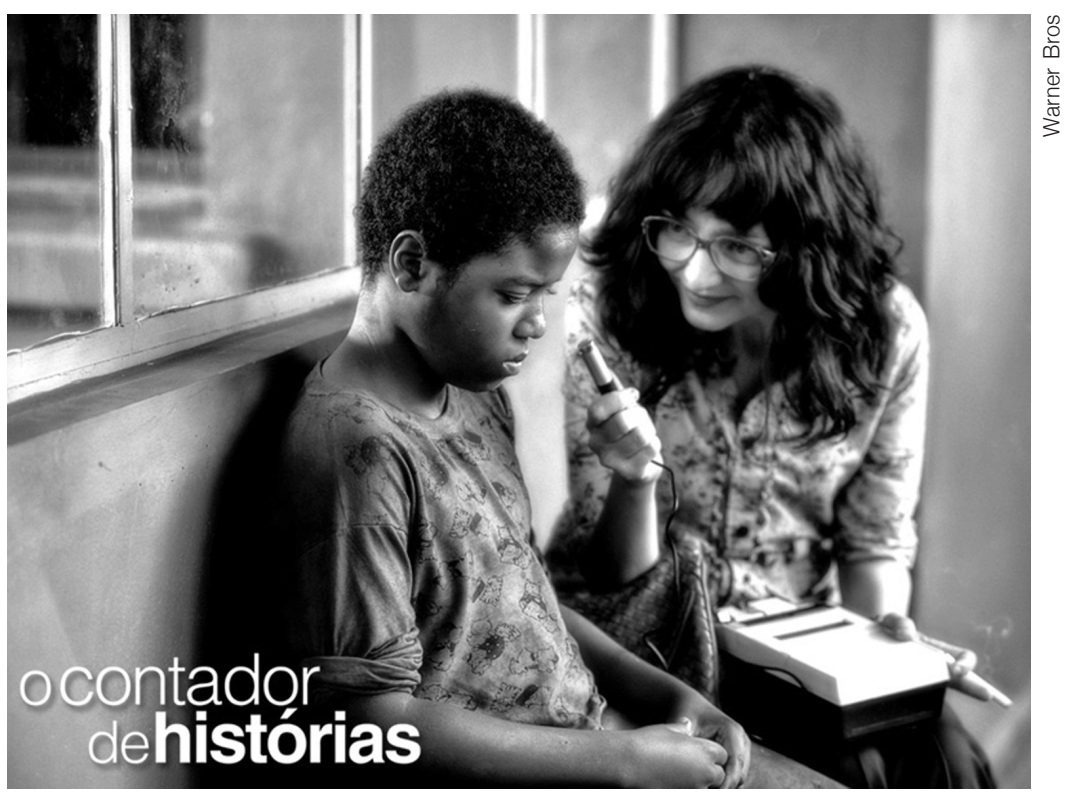

Cena do filme O contador de histórias, de Luiz Villaça. 
nos remetem a uma história acontecida com alguém, em algum lugar, em um determinado período.

Roberto Carlos Ramos, de acordo com os escritos sobre o filme, nasceu em uma favela de Belo Horizonte. Era o filho caçula de dez irmãos. Sua história começa durante os anos de 1970, quando, aos seis anos de idade, foi escolhido pela mãe para ser interno em uma instituição oficial que, segundo a propaganda de televisão, preparava jovens para serem advogados, médicos, engenheiros. A realidade se revelou, no entanto, bastante diferente para o menino até então criado em uma família e dotado de pródiga imaginação. Aos sete anos, foi transferido para outro setor da Instituição e passou a conviver com crianças de até 14 anos. Até os 13 anos, Roberto ainda era analfabeto. Na adolescência, foi novamente transferido a uma Instituição onde as leis eram ainda mais duras e incluíam violência psicológica, castigos corporais e total ausência de esperança ou possibilidade de mudança. Roberto Carlos e alguns internos logo descobriram o caminho das ruas, das drogas e dos pequenos delitos. Em busca de segurança, tentou associar-se a um grupo ainda mais violento. Nessa época teve contato com as drogas e acumulava mais de cem tentativas de fugas. Foi considerado irrecuperável. Certo dia, porém, recebeu a visita da psicóloga francesa Margherit Duvas, que se aproximou dele com duas expressões há muito não ouvidas: "com licença" e "por favor". Este foi, ainda segundo a sinopse do filme, o início de uma emocionante história de afeto e dedicação que rende frutos até hoje.

De fato o filme parte da história real vivida por Roberto Carlos, uma criança de seis anos. A década é 1970. O período histórico é o militar, que, em novembro de 1967, autorizou o Poder Executivo a instituir a Fundação Estadual do Bem-Estar do Menor - a Febem. Durante os anos de 1970, as propagandas do governo incentivavam, pelos mais diversos meios de comunicação, as famílias a colocarem seus filhos na instituição, uma vez que esta se destinava a "formular e implantar programas de atendimento a menores em situação irregular, prevenindo a marginalização e oferecendo oportunidades de promoção social”. Após ouvir a propaganda do governo, a mãe de Roberto Carlos decide encaminhá-lo para lá, à sua revelia.

O filme então aborda, entre vários temas, a violência física e mental, o abandono, o instinto de sobrevivência e o medo que, de tanto temer, se transforma em ira. Nesse cenário, a imaginação foi o lugar escolhido por Roberto Carlos para se refugiar e criar forças para não morrer, enfrentando um duplo desafio: o de perceber como funcionavam as leis da Instituição e o de manter viva a capacidade de criar histórias para transformar a realidade.

\section{OUVIR COM OS OLHOS. LER COM OS OUVIDOS}

Em depoimento, Luiz Villaça conta que, certa vez, lia um livro de histórias infantis para seu filho dormir. Após o sono do filho, ele continuou a ler o livro e descobriu que uma das histórias era a de Roberto Carlos. Foi quando lhe veio 
comunicação \& educação • Ano XVII • número 1 • jan/jun 2012

a vontade de fazer um filme sobre aquela história e personagem - um filme que nasceu do desejo e do amor pelo objeto a ser filmado, sem medo de arriscar, de arriscar-se. No fundo, brotou da consciência de saber que o cinema tem a capacidade de tornar possível e visível o aparentemente impalpável. Ainda no tocante ao fazer cinema, cabe observar a ficha técnica e as pessoas envolvidas na feitura do filme - exercício que pede um olhar atento ao conjunto necessário para que ele pudesse existir. Os filmes podem ter datas específicas, mas o mesmo não ocorre com as temáticas e, principalmente, com as possibilidades que eles nos trazem de leitura e debate sobre assuntos que envolvem tanto a realidade do país como seu processo de criação. Basta atualizar o olhar - e esse é um dos aspectos a serem debatidos: a construção do olhar sobre as produções culturais, no caso o cinema, e os efeitos que elas produzem em cada uma das épocas históricas.

Outra sugestão para análise dos processos de produção e criação de um filme e da temática proposta é a de um estudo comparativo entre o filme o Contador de Histórias, de Luiz Villaça, e Bicho de Sete Cabeças, de Laís Bodansky, proposto na Revista Comunicação E Educação de janeiro/julho de $2011^{4}$. Ambos, apesar das diferenças entre si, trazem também muitas semelhanças - mesmo que estas apareçam invertidas em alguns aspectos. Os filmes partem de histórias reais, vividas por pessoas com idades diferentes. No filme Bicho de Sete Cabeças, Neto é um adolescente de 17 anos e Roberto Carlos, uma criança de seis. A década é a mesma: 1970 - época em que as lutas antimanicomiais iniciadas nos anos de 1960 na Itália cresciam também no Brasil. As duas histórias narram as experiências dos personagens dentro de Instituições Oficiais. Ambos são vítimas da intolerância não apenas expressa nas relações sociais, mas também daquela instituída pelas estruturas de poder, seja hospitalar, político ou familiar.

Especificamente nas relações humanas e familiares, as figuras do pai no filme Bicho de Sete Cabeças e da mãe em Contador de Histórias são os focos das histórias contadas. Se o pai é presença que marca a vida de Neto, a mãe, durante sua infância, e depois a psicóloga são as referências na vida de Roberto Carlos. Aqui vale citar um trecho da Carta ao Pai, em que Kafka (p. 7) escreveu:

Eu era uma criança medrosa: é claro que apesar disso também era teimoso como são as crianças; certamente também minha mãe me mimou, mas não posso crer que fosse um menino difícil de lidar, nem que uma palavra amável, um silencioso levar pela mão, um olhar bondoso não pudessem conseguir de mim tudo o que quisesse.

Ironia da vida. Se em Bicho de Sete Cabeças esses gestos e toques de afeto não existiram, e o pai conduziu o filho ao Sanatório, o avesso dessa história foi a de Roberto Carlos. Em O Contador de Histórias, é exatamente pelo afeto e pelo desejo de um futuro melhor para o filho que a mãe o levou ao internato em uma instituição oficial - como também foi o olhar atento e uma palavra amável da psicóloga Margherit Duvas que ajudaram Roberto Carlos a se tornar o que é: pedagogo, contador de histórias e pai de 20 crianças antes consideradas irrecuperáveis, como ele.

Quanto ao ato de ensinar, sugiro a leitura do texto A atenção em Simone $W e i \check{l}$, de Ecléa Bosi, para compreendermos a importância do olhar atento para o que existe de superlativo em todos os seres vivos. 